Article

\title{
Corrosion Behavior of SA508 Coupled with and without Magnetite in EDTA-Based Solutions
}

\author{
Yeong-Ho Son ${ }^{1,2,3}$, Soon-Hyeok Jeon ${ }^{1}$, Geun Dong Song ${ }^{1}$, Jong Hyeon Lee ${ }^{2, *(1)}$ and \\ Do Haeng Hur $1, *$ (D) \\ 1 Nuclear Materials Research Division, Korea Atomic Energy Research Institute, 989-111, Daedeok-daero, \\ Yuseong-gu, Daejeon 34057, Korea; syhm0907@kaeri.re.kr (Y.-H.S.); junsoon@kaeri.re.kr (S.-H.J.); \\ sgd84@kaeri.re.kr (G.D.S.) \\ 2 Department of Advanced Materials Engineering, Chungnam National University, 99, Daehak-ro, \\ Yuseong-gu, Daejeon 34134, Korea \\ 3 R\&D Center, SeAH Changwon Special Steel Corporation, 147, Jeokhyeon-ro, Seongsan-gu, Changwon, \\ Gyeongnam 51708, Korea \\ * Correspondence: jonglee@cnu.ac.kr (J.H.L.); dhhur@kaeri.re.kr (D.H.H.); \\ Tel.: +82-42-821-6596 (J.H.L.); +82-42-868-8388 (D.H.H.)
}

Received: 4 October 2018; Accepted: 23 October 2018; Published: 24 October 2018

\begin{abstract}
The effects of magnetite on the corrosion behavior of SA508 were studied in 10\% and 20\% EDTA-based chemical cleaning solutions at $93^{\circ} \mathrm{C}$ and $121^{\circ} \mathrm{C}$ using electrochemical and immersion tests. SA508 was the anode of the galvanic pair between SA508 and magnetite. The galvanic coupling shifted the mixed corrosion potential of SA508 in the positive direction and thus increased its corrosion rate. The increase of the EDTA concentration and solution temperature led to an increase in the extent of the galvanic effect.
\end{abstract}

Keywords: chemical cleaning; magnetite; electrodeposition; polarization; galvanic corrosion; steam generator

\section{Introduction}

Corrosion products are released from the surface of feed water piping in the secondary water system of a pressurized water reactor. They are transported into the steam generator (SG) and settled down on the top of the tubesheet or deposited onto the surfaces of the SG tubes and their support structures. These phenomena can lead to various problems such as the local concentration of chemical impurities within deposits, a decrease of heat transfer efficiency, a blockage in waterway, and a corrosion acceleration of SG materials [1-3].

To mitigate these problems, various methods for the removal of the sludge or deposits have been used: high pressure water lancing, ultrasonic cleaning, and chemical cleaning. Among them, chemical cleaning processes have been widely used in SGs to dissolve out the sludge and deposits accumulated in regions even where it is hard for the cleaning solutions to reach in the secondary side of the SGs. For the chemical cleaning processes, controlling the corrosion of materials within an allowable limit is as important as achieving high removal effectiveness.

It has been reported that a galvanic coupling with magnetite accelerates the corrosion of secondary system materials: carbon steel [4-6], alloy 600 [7] and alloy 690 [8,9] in various environments simulating the secondary conditions of SGs. Most of the tubes and heated crevices in operating SGs are covered with deposits or sludge. The deposits and sludge are porous in nature enough to allow the faulted secondary water to penetrate the surfaces of the SG materials $[10,11]$. The major component of these deposits and sludge is essentially magnetite. This means that actual corrosion phenomena 
are occurring in a condition where the surfaces of the SG materials are contacted with magnetite. Because magnetite has a high electrical conductivity of $2.5 \times 10^{4} / \Omega \mathrm{cm}$ at $25^{\circ} \mathrm{C}$ [12], magnetite behaves as a metal. Therefore, a galvanic coupling between the surfaces of the SG materials and magnetite is also anticipated. Consequently, the effects of the magnetite deposit or sludge should be considered in evaluating the corrosion behavior of steam generator materials under chemical cleaning conditions. However, during the chemical cleaning processes in operating SGs, the corrosion measurement or monitoring of materials has been performed without consideration of a galvanic effect coupled with magnetite.

In this study, the effects of magnetite on the corrosion behavior of SA508 material were investigated in EDTA (ethylenediaminetetraacetic acid) based chemical cleaning solutions at $93^{\circ} \mathrm{C}$ and $121^{\circ} \mathrm{C}$. SA508 low alloy was chosen as a test material because this alloy is used as the tubesheet material of SGs and is susceptible to corrosion. In addition, magnetite transported into SGs settles and accumulates preferentially on the top of the tubesheet. Galvanic corrosion between SA508 and magnetite was measured in immersion tests, predicted using the polarization curves, and verified through zero resistance ammeter (ZRA) measurements.

\section{Materials and Methods}

\subsection{Test Material and Solutions}

SA508 specimens were cut into a size of $10 \mathrm{~mm} \times 5 \mathrm{~mm} \times 1 \mathrm{~mm}$ for the electrochemical tests and $30 \mathrm{~mm} \times 20 \mathrm{~mm} \times 1 \mathrm{~mm}$ with a $6.5 \mathrm{~mm}$ diameter hole for the immersion tests. All specimens were ground using silicon carbide papers down to 1000-grit. The chemical composition of SA508 is given in Table 1.

Table 1. Chemical composition of SA508 (wt.\%).

\begin{tabular}{ccccccccc}
\hline $\mathbf{C}$ & $\mathbf{S i}$ & $\mathbf{M n}$ & $\mathbf{P}$ & $\mathbf{S}$ & $\mathbf{N i}$ & $\mathbf{C r}$ & $\mathbf{M o}$ & $\mathbf{F e}$ \\
\hline 0.199 & 0.051 & 1.52 & 0.005 & 0.006 & 0.987 & 0.232 & 0.582 & Bal. \\
\hline
\end{tabular}

The compositions of the chemical cleaning solutions used in this work were as follows: $10 \mathrm{wt} . \%$ EDTA (or, 20 wt. $\%$ EDTA) +1 wt. $\% \mathrm{~N}_{2} \mathrm{H}_{4}+1 \mathrm{wt} . \%$ CCI-801 (a corrosion inhibitor). The final $\mathrm{pH}$ of all test solutions was adjusted to 7.0 using $\mathrm{NH}_{4} \mathrm{OH}$ at $25^{\circ} \mathrm{C}$. These EDTA-based solutions have been used to dissolve and remove magnetite sludge that accumulates in operating SGs of pressurized water reactors (PWRs) $[13,14]$. The solutions were prepared using deionized water with a resistivity near $18 \mathrm{M} \Omega \cdot \mathrm{cm}$ and reagent grade chemicals. No attempt was made to control the content of dissolved oxygen in the test solutions before and during the tests.

\subsection{Preparation of Working Electrodes for the Electrochemical Tests}

To make a SA508 working electrode for the electrochemical test, a SA508 specimen with a dimension of $10 \mathrm{~mm} \times 5 \mathrm{~mm} \times 1 \mathrm{~mm}$ was spot-welded to a pure iron wire, which was then covered with a polytetrafluoroethylene tube for electrical insulation. A heat resistant silicon resin was coated around the weld junction to prevent the test solution from penetrating into any remaining crevice there.

To evaluate the electrochemical corrosion behavior of magnetite itself, a compact and rigid magnetite working electrode is needed. Various methods for the manufacture of magnetite electrodes have been reported in the literature: casting molten magnetite $[15,16]$, sintering magnetite powder [17,18], sputtering deposition [19], etc. However, a simpler method was recently developed to electrodeposit a magnetite layer onto carbon steel and Ni-based alloy substrates [20-23], and was verified to be useful for making electrochemical electrodes [4-9].

In this work, a magnetite working electrode was prepared by the electrodeposition of a thick magnetite layer over the whole surface of the SA508 working electrode stated above. The electrodeposition solution was a mixture of $2 \mathrm{M} \mathrm{NaOH}, 0.1 \mathrm{M}$ triethanolamine and $0.043 \mathrm{M}$ 
$\mathrm{Fe}_{2}\left(\mathrm{SO}_{4}\right)_{3}$. The electrodeposition of the magnetite layer was done in a three-electrode cell using a PAR273 potentiostat with the Power suite software. A saturated calomel electrode (SCE) was used as the reference electrode and a platinum wire was used as the counter electrode. The magnetite layer was electrodeposited in the deposition solution at an applied potential of $-1.05 \mathrm{~V}$ vs. SCE for $10 \mathrm{~h}$ at $80^{\circ} \mathrm{C}$. After the electrodeposition, the magnetite-deposited electrode was rinsed with deionized water and dried in an oven at $60^{\circ} \mathrm{C}$ for $5 \mathrm{~min}$. Figure 1 shows the schematic of the SA508 and magnetite working electrode.

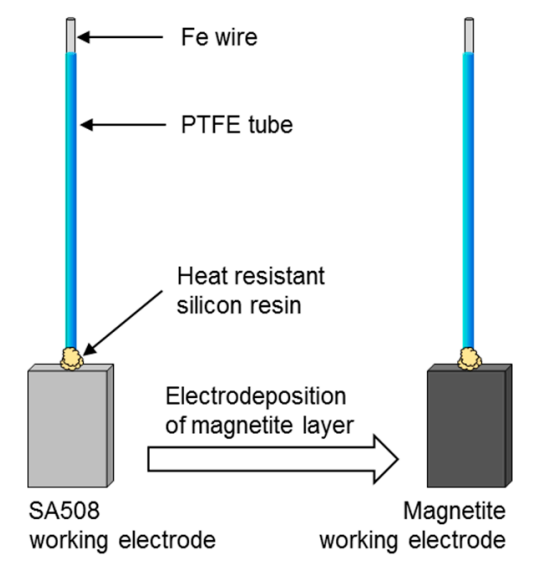

Figure 1. Schematic of a magnetite working electrode prepared using the electrodeposition method.

The morphology of the electrodeposited magnetite layer was observed using a scanning electron microscope (SEM, JEOL, Tokyo, Japan). The structure of the magnetite layer was determined by X-ray diffraction (XRD) with a Rigaku D/Max-2500 diffractometer ( $\mathrm{Cu}-\mathrm{K} \alpha$ radiation, Rigaku, Tokyo, Japan). The magnetite deposited electrode was also milled to measure the thickness of the layer by a focused ion beam (FIB, FEI, Hillsboro, CA, USA) toward the vertical direction of the layer.

\subsection{Electrochemical Corrosion Tests}

Two different electrochemical techniques were used to study the galvanic corrosion between SA508 and magnetite in $10 \%$ EDTA-based chemical cleaning solution at $93{ }^{\circ} \mathrm{C}$ : potentiodynamic polarization and ZRA measurement. The potentiodynamic polarization tests were carried out in a conventional corrosion cell with three electrodes. A SCE and a platinum coil were used as the reference and counter electrode, respectively. After the open circuit potential (OCP) was stabilized, the polarization scan was started from the OCP to the cathodic or anodic direction with a scan rate of $1 \mathrm{mV} / \mathrm{s}$. The individual anodic and cathodic polarization curves were finally combined into a graph. The corrosion current densities $\left(i_{\text {corr }}\right)$ of SA508 and magnetite at the individual corrosion potentials $\left(E_{\text {corr }}\right)$ were calculated by the Tafel extrapolation of the corresponding cathodic curve.

The actual galvanic corrosion behavior between SA508 and magnetite was also measured using a Gamry Reference 600 instrument (Gamry, Warminster, PA, USA) potentiostat in the ZRA mode. In this case, the area ratio between the SA508 and magnetite electrode was equivalent. After the OCP was stabilized, the two electrodes were electrically connected through the ZRA. The variation of the current density of the SA508 coupled with magnetite was measured for $1500 \mathrm{~s}$.

In addition, the corrosion current density of SA508 over time was measured using the linear polarization (LP) technique in $10 \%$ EDTA-based chemical cleaning solution at $93{ }^{\circ} \mathrm{C}$ for $1500 \mathrm{~s}$. In this case, the potential was scanned from $10 \mathrm{mV}$ more active to $10 \mathrm{mV}$ more noble than the corrosion potential at a rate of $0.2 \mathrm{mV} / \mathrm{s}$. The Tafel slopes of the anodic and cathodic reactions, which are needed to calculate the corrosion rate, were obtained from the polarization curves of SA508. All electrochemical tests were conducted at least four times per condition to confirm their reproducibility. 


\subsection{Immersion Tests}

Immersion tests for the weight loss measurement were basically conducted in two different conditions using separate autoclaves: corrosion coupons were in contact with magnetite powder in one condition, and they were directly exposed to the test solution without magnetite in the other condition.

The top of the SG tubesheet is covered with porous magnetite, which is accumulated in service. Therefore, an immersion cell was designed to simulate corrosion occurring in an occluded region where porous magnetite is accumulated and thus the supply of the chemical cleaning solution is insufficient. As shown in Figure 2, the immersion cell consisted of an upper and lower cap, glass filter, container, and specimen holder. All the components except for the glass filters were made of Teflon to avoid any galvanic corrosion between the SA508 and cell components. Three SA508 coupons for the weight loss measurement were placed on the specimen holder. Magnetite powder was tightly packed up to the maximum level of the container so that all surface areas of the specimens kept a state of contact with the magnetite powder during the test. The particle size and purity of the magnetite powder were $1.0 \mu \mathrm{m}$ on average and $99.9 \%$, respectively. Several holes were machined in the upper and lower cap enabling the chemical cleaning solution to access through the glass filters the cell. Glass filters with a pore size of $0.5 \mu \mathrm{m}$ were used to prevent magnetite powder from oozing out of the cell. The end part of the thermocouple and the center of the specimens were positioned at the same height. In the case of the SA508 specimens without coupling to magnetite powder, the corrosion coupons were freely located on the specimen holder so that they were directly exposed to the chemical cleaning solutions in a different autoclave.

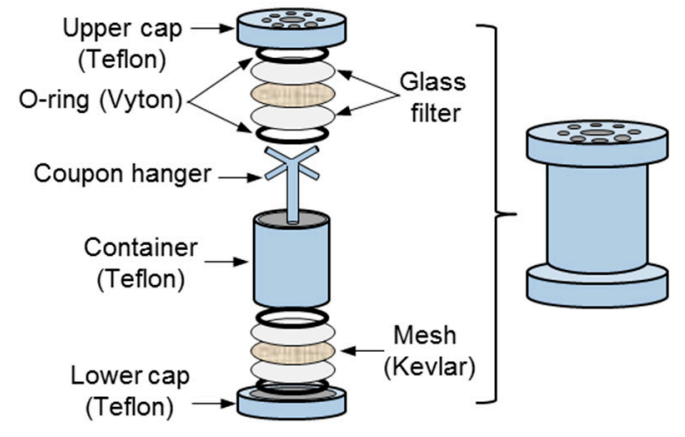

(a)

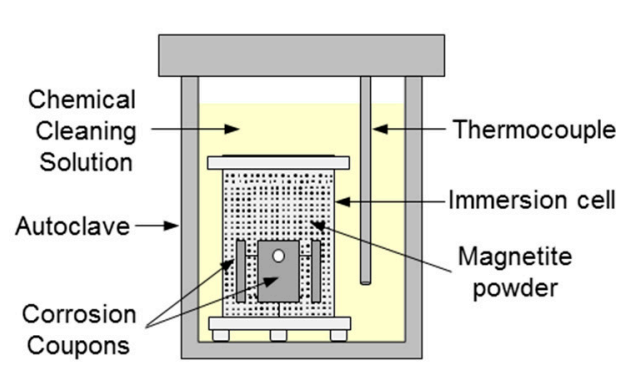

(b)

Figure 2. Schematics of the apparatus used for the immersion corrosion tests: (a) immersion cell, and (b) arrangement in the autoclave.

All immersion tests were conducted in Ti-autoclaves at $93^{\circ} \mathrm{C}$ and $121{ }^{\circ} \mathrm{C}$ for $40 \mathrm{~h}$. After the tests, specimens were ultrasonically cleaned in deionized water, dried in an oven at $60^{\circ} \mathrm{C}$, and then weighed using an electronic balance with a resolution of $10 \mu \mathrm{g}$. The corrosion morphology of the specimens was also observed with SEM.

\section{Results and Discussion}

\subsection{Electrodeposited Magnetite Layer}

Figure 3 shows the SEM images of the magnetite layer electrodeposited onto the SA508 substrate. The magnetite layer seems to grow in a polyhedral or pyramidal shape. This magnetite layer was so compact and homogeneous that any defects such as micro-cracks, pores, and interstices were not observed in the layer and at the interface between the magnetite layer and the substrate. The thickness of the magnetite layer was measured to be approximately $110 \mu \mathrm{m}$ from the cross-section. 

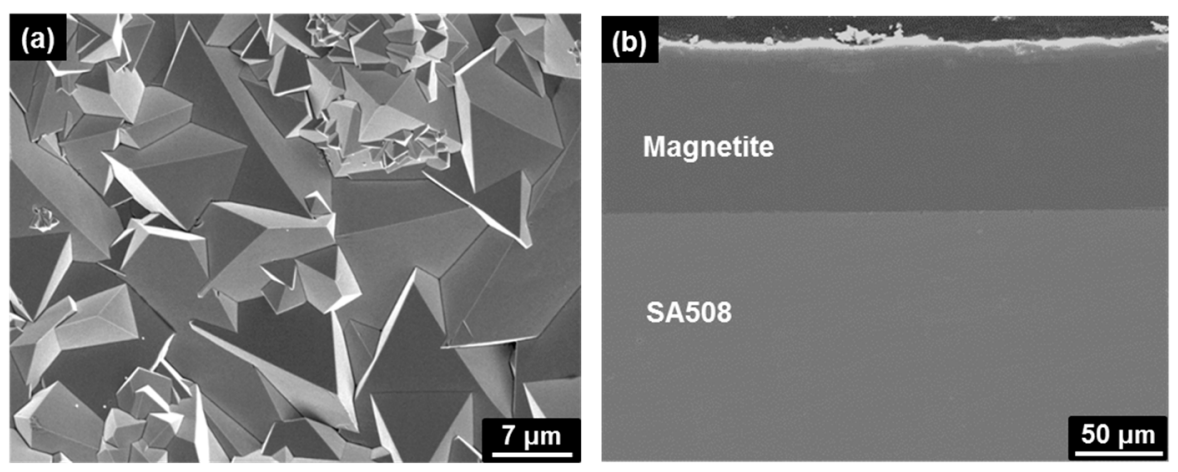

Figure 3. SEM images of the magnetite layer electrodeposited on the SA508 substrate: (a) surface, and (b) cross-section.

In addition, as shown in Figure 4, the XRD patterns of this layer coincided with those of pure crystalline magnetite (JCPDS card No. 01-086-1351). These results therefore indicate that the electrodeposited magnetite working electrode is very suitable to evaluate the electrochemical corrosion behavior of the magnetite electrode itself, without penetration of the test solution into the substrate through the magnetite layer.

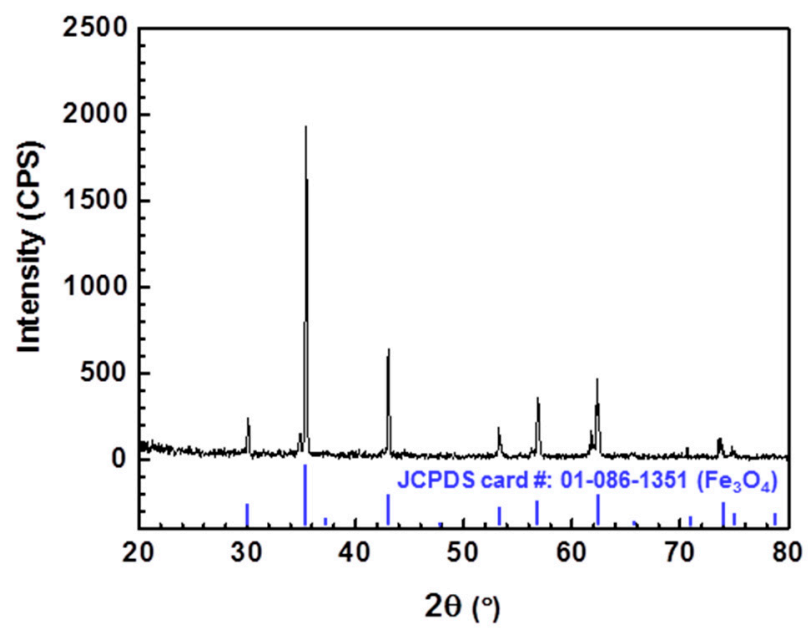

Figure 4. X-ray diffraction patterns of the electrodeposited magnetite layer.

\subsection{Electrochemical Corrosion Behavior}

Figure 5 shows the potentiodynamic polarization curves of the SA508 and magnetite electrodes in $10 \%$ EDTA-based chemical cleaning solution at $93^{\circ} \mathrm{C}$. The corrosion rate of SA508 will increase rapidly as the potential increases from its corrosion potential. The corrosion potential of SA508 was about 470 $\mathrm{mV}$ lower than that of magnetite and the anodic curve of SA508 following a Tafel behavior intersected the cathodic curve of the magnetite. Consequently, when these two materials contact galvanically, it is obvious that SA508 becomes the anode of the galvanic pair and its corrosion rate significantly increases. Here, if equal areas of the two materials are coupled, the galvanic potential $\left(E_{\text {couple }}\right)$ and the galvanic current density ( $i_{\text {couple }}$ ) of the galvanic pair can be obtained by application of the mixed potential theory at the point where the above two polarization curves intersect.

Table 2 summarizes the electrochemical corrosion parameters calculated from the polarization curves by the Tafel extrapolation method and mixed potential theory. As shown in Table 2, when equal areas of SA508 and magnetite are galvanically coupled, the corrosion rate of SA508 will increase by a factor of approximately 600 , from $0.028 \mathrm{~mA} / \mathrm{cm}^{2}$ to $16.85 \mathrm{~mA} / \mathrm{cm}^{2}$. Therefore, this result agrees with the previous results that a galvanic coupling increased the corrosion rate of the materials coupled to magnetite in various aqueous solutions $[5,7,9,24]$. On the other hand, the Tafel constants of SA508 
estimated from the polarization curves were $0.1034 \mathrm{~V}$ for the anodic reaction and $0.0923 \mathrm{~V}$ for the cathodic reaction. These values were used to calculate the corrosion rate of SA508 with the testing time using the LP method later.

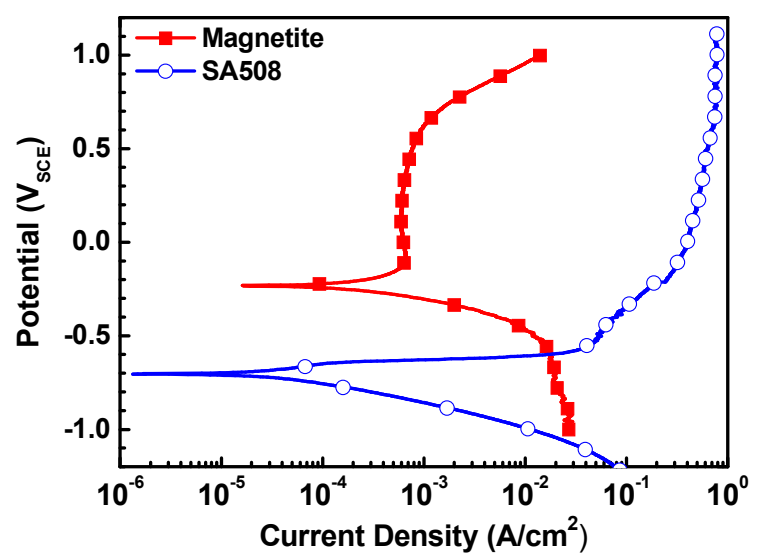

Figure 5. Polarization curves of SA508 and magnetite electrodes in 10\% EDTA-based chemical cleaning solution at $93{ }^{\circ} \mathrm{C}$.

Table 2. Electrochemical corrosion parameters of SA508 and magnetite in $10 \%$ EDTA solution at $93{ }^{\circ} \mathrm{C}$.

\begin{tabular}{ccc}
\hline Corrosion Parameter & SA508 & Magnetite \\
\hline$E_{\text {corr }}\left(\mathrm{mV}_{\mathrm{SCE}}\right)$ & $-704 \pm 11$ & $-233 \pm 9$ \\
$E_{\text {couple }}\left(\mathrm{mV}_{\mathrm{SCE}}\right)$ & \multicolumn{2}{c}{$-599 \pm 9$} \\
$i_{\text {corr }}\left(\mathrm{mA} / \mathrm{cm}^{2}\right)$ & $0.028 \pm 0.004$ & $0.171 \pm 0.021$ \\
$i_{\text {couple }}\left(\mathrm{mA} / \mathrm{cm}^{2}\right)$ & \multicolumn{2}{c}{$16.851 \pm 1.17$} \\
\hline
\end{tabular}

Figure 6 shows the SEM images of the surface and cross-section of a magnetite working electrode after the polarization test. Compared to the feature before the test in Figure 3, it can be seen that the surface is generally corroded but maintains its integrity enough to prevent the exposure of the substrate to the test solution. In this work, the magnetite specimen deposited onto a SA508 working electrode was used as a magnetite working electrode for the electrochemical measurement. Therefore, it is clearly verified that the polarization curves of the magnetite electrodes were obtained from the reactions occurring on the surface of the magnetite itself without interference from the SA508 substrate.
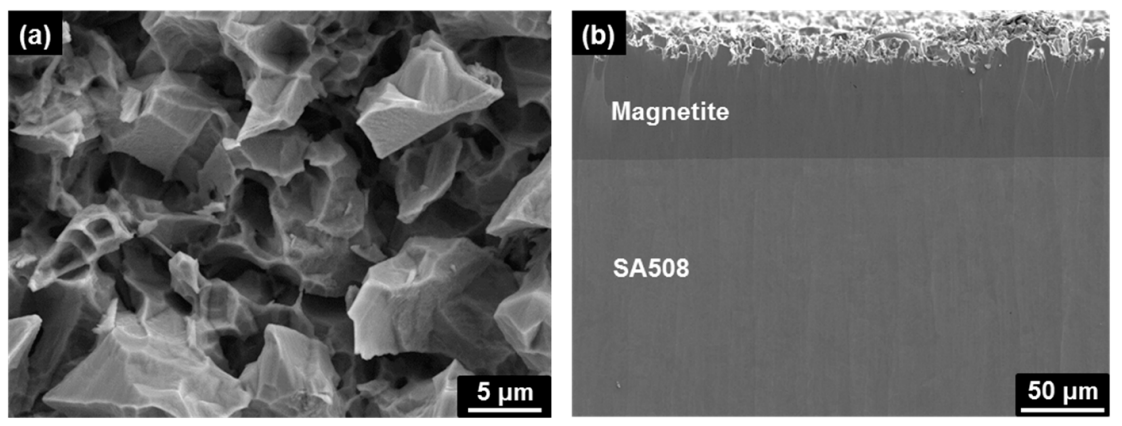

Figure 6. SEM images of the magnetite layer electrodeposited on the SA508 substrate after the polarization test in 10\% EDTA-based chemical cleaning solution at $93{ }^{\circ} \mathrm{C}$ : (a) surface, and (b) cross-section.

Figure 7 shows the actual galvanic potential and galvanic current density of SA508 coupled with magnetite, which were obtained from the ZRA measurements in 10\% EDTA-based solution at $93{ }^{\circ} \mathrm{C}$. These data were measured in a condition where equal areas of SA508 and magnetite were coupled. The individual corrosion potentials of uncoupled-freely corroding SA508 and magnetite 
were also monitored for comparison. The corrosion current density of the uncoupled SA508 was also superimposed, which was determined by the LP technique in the same test solution. As shown in Figure $7 \mathrm{a}$, the galvanic potential of the SA508 coupled with magnetite shifted to the positive direction by approximately $100 \mathrm{mV}$ compared to that of the uncoupled SA508. This means that this galvanic coupling puts SA508 in a more oxidizing condition. Actually, the galvanic corrosion rate of the SA508 coupled with magnetite was approximately 550-600 times higher than that of the uncoupled SA508, as shown in Figure $7 \mathrm{~b}$. These results were in good agreement with the results predicted from the polarization curves shown in Figure 5 and Table 2. These galvanic effects were obtained when the SA508 and magnetite were coupled with an equal area. Therefore, if these two materials are contacted with an unfavorable area ratio of a large cathode (magnetite) and a small anode (SA508), it is expected that the galvanic potential of the coupled SA508 shifts to a more positive direction, and the resultant galvanic corrosion rate of the coupled SA508 is more accelerated.

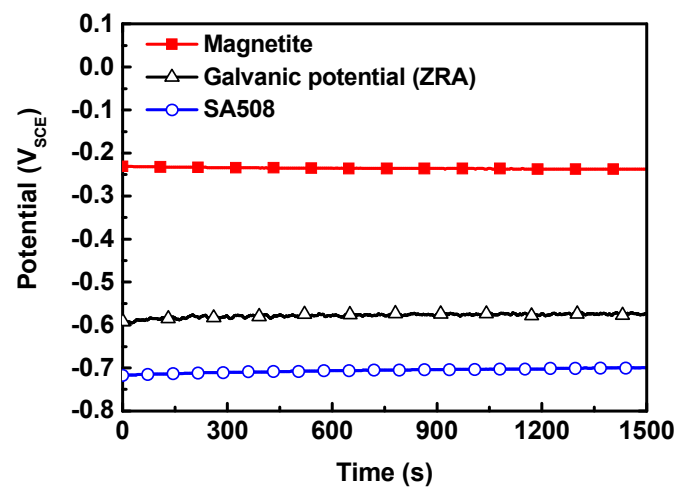

(a)

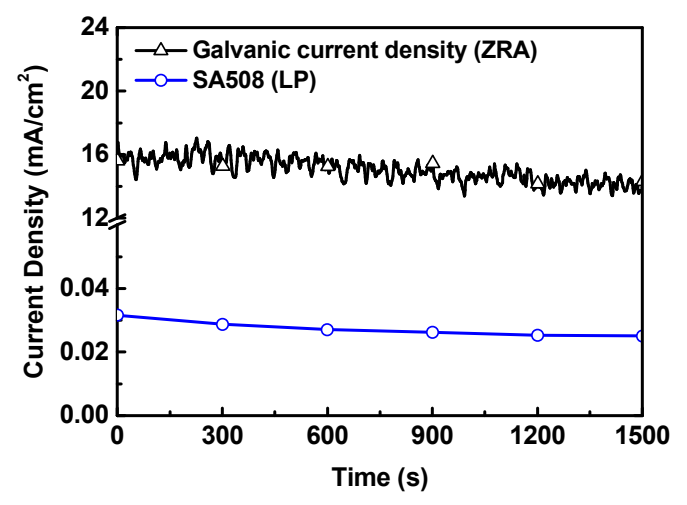

(b)

Figure 7. Effect of magnetite on: (a) the corrosion potential; and (b) corrosion current density in $10 \%$ EDTA-based solution at $93^{\circ} \mathrm{C}$.

\subsection{Immersion Corrosion Behavior}

Figure 8 shows the weight loss data of the SA508 obtained from the immersion tests. The SA508 coupons coupled within magnetite powder always had a much higher weight loss rate than the uncoupled-freely corroding coupons regardless of the EDTA concentrations and temperatures. The weight loss rate of the coupled SA508 also increased with the increase of the EDTA concentration at each temperature, whereas the freely corroding SA508 without contact with the magnetite powder was not affected. These results again verify that the galvanic coupling between the SA508 and magnetite powder accelerates the corrosion rate of SA508.

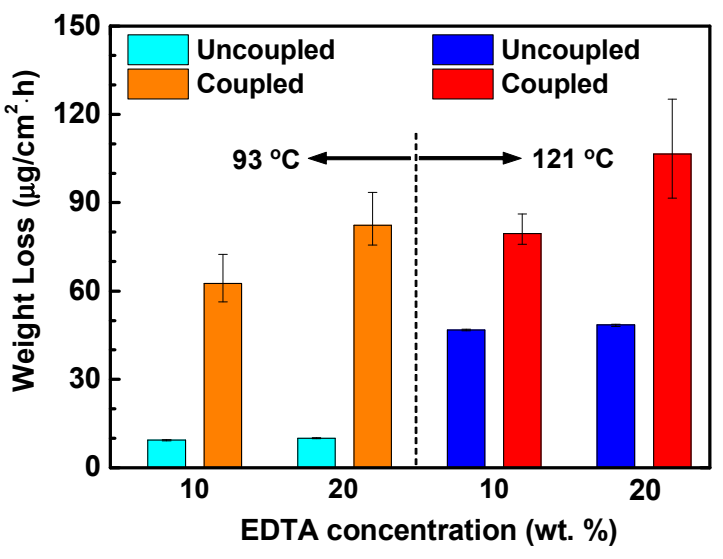

Figure 8. Effect of magnetite on: (a) the corrosion potential; and (b) corrosion current density in $10 \%$ EDTA-based solution at $93^{\circ} \mathrm{C}$. 
Here, the extent of the accelerated-corrosion by the galvanic coupling with the magnetite powder was significantly small compared to the results obtained from the electrochemical measurements. This is because the immersion cell in Figure 2 was designed to simulate an occluded region where porous magnetite is accumulated and thus the access of the chemical cleaning solution is restricted. From the electrochemical test results, however, it is anticipated that more accelerated-corrosion would occur in regions such as open crevices and on the exposed metal surfaces of the tubesheet, where the chemical cleaning solution can freely circulate and thus be refreshed. In these regions, therefore, because the ratio of the cathode (magnetite) to anode (SA508) area would be much larger than the equivalent area ratio (1:1), the galvanic effect would be greater. As described in the Introduction Section, because magnetite deposited on the tubesheet of a SG is very porous, numerous micro-galvanic cells can be formed on the tubesheet surface beneath the porous magnetite deposit. Under this condition, the corrosion rate of SA508 is expected to significantly increase during the chemical cleaning processes. This situation is schematically depicted in Figure 9.

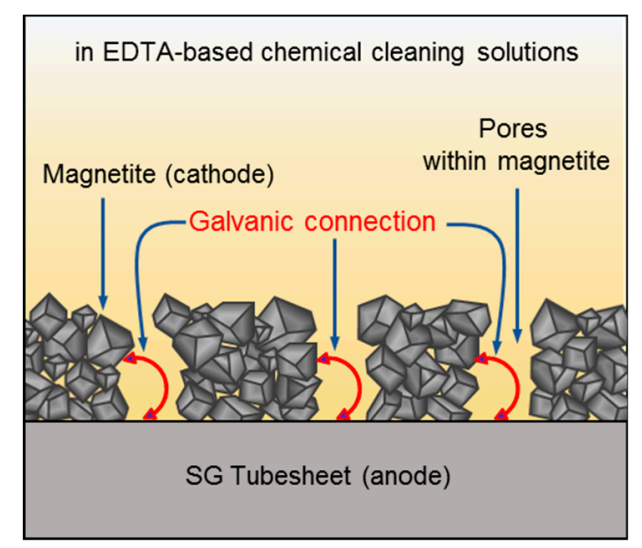

Figure 9. Schematic of a galvanic corrosion mechanism within magnetite piles accumulated on the top of the SG tubesheet during the chemical cleaning process.

In Figure 8, the increase rate of the weight loss of SA508 by the coupling with the magnetite powder was smaller at $121{ }^{\circ} \mathrm{C}$ than that at $93^{\circ} \mathrm{C}$. This can be caused by the difference of the amount of free-EDTA which affects the corrosion at the two test temperatures. The magnetite dissolution rate in the EDTA-based chemical cleaning solutions at $130^{\circ} \mathrm{C}$ was approximately two times faster than that at $90{ }^{\circ} \mathrm{C}$ [25]. Because the dissolved iron ions are chelated by EDTA, free-EDTA is rapidly consumed at a higher temperature. The amount of free-EDTA also rapidly decreases through thermal decomposition at a higher temperature [26-28].

Figure 10 shows the corrosion morphology of the uncoupled and coupled SA508 coupons with magnetite powder after the immersion tests. It is clearly confirmed that the surfaces of SA508 were severely attacked when the SA508 coupons were coupled with the magnetite powder and tested at a higher temperature.

In this paper, the increased corrosion rate of SA508 by galvanic coupling with magnetite was demonstrated by the immersion tests and predicted by the polarization curves as well as verified from the ZRA measurements. When applying EDTA-based chemical solvents to a SG, corrosion acceptance guidelines should be fulfilled for the complete chemical cleaning process. The allowable corrosion limit is plant specific and dependent on the materials of the SG components [3]. However, the galvanic corrosion effect by magnetite deposit has not been considered until now. The critical regions in terms of an accelerated galvanic corrosion are as follows: the ligament between a tube hole and adjacent flow holes in the tube support structure, and the crevice around a tube on the top of the tubesheet. Especially, because the tubesheet is made of SA508 low alloy steel susceptible to corrosion, the crevices of the top of the tubesheet seem to be vulnerable to the galvanic corrosion by magnetite. The resulting increase in the annular gap and depth of the crevices would decrease the tube integrity. Therefore, it is 
recommended that corrosion monitoring is performed to measure and control the galvanic corrosion between SG materials and magnetite sludge during chemical cleaning processes in SGs.
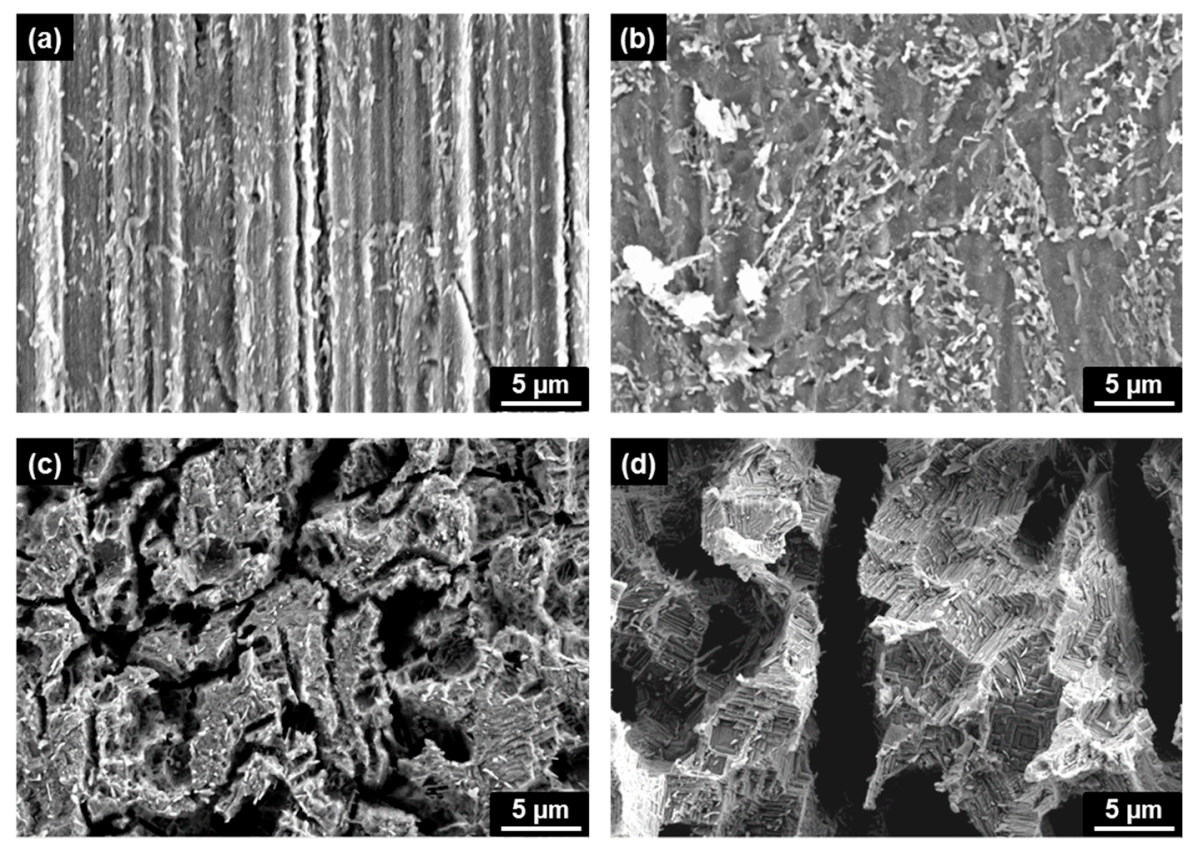

Figure 10. Corrosion morphology of SA508 coupons after the immersion test: (a) uncoupled SA508 in $10 \%$ EDTA-based solution at $93{ }^{\circ} \mathrm{C}$; (b) uncoupled SA508 in $20 \%$ EDTA-based solution at $121{ }^{\circ} \mathrm{C}$; (c) SA508 coupled with magnetite in $10 \%$ EDTA-based solution at $93{ }^{\circ} \mathrm{C}$; and (d) SA508 coupled with magnetite in $20 \%$ EDTA-based solution at $121^{\circ} \mathrm{C}$.

\section{Conclusions}

The effects of magnetite on the corrosion behavior of SA508 tubesheet material of SGs were investigated in EDTA-based chemical cleaning solutions at $93^{\circ} \mathrm{C}$ and $121^{\circ} \mathrm{C}$. From the polarization measurements, the corrosion rate of SA508 was predicted to increase significantly when SA508 was galvanically coupled with magnetite. The ZRA measurements also showed that SA508 was the anodic member of the galvanic pair between the two materials as well as verified the increased corrosion rate of SA508 coupled with magnetite. SA508 within magnetite powder produced a more severe corrosion than freely corroding SA508 without contact with magnetite in the immersion tests. Therefore, it is recommended that the galvanic corrosion effect between SA508 and magnetite should be considered when the corrosion measurement is performed during the chemical cleaning processes in SGs.

Author Contributions: Y.-H.S. performed the overall experiments and wrote the draft manuscript; S.-H.J. and G.D.S. analyzed the deposited-magnetite layers; J.H.L. reviewed the manuscript; and D.H.H. conceived and supervised this work.

Funding: This work was supported by the National Research Foundation of Korea (NRF) grant funded by the Korea government (No. 2017M2A8A4015159).

Conflicts of Interest: The authors declare no conflict of interest. The funders had no role in the design of the study; in the collection, analyses, or interpretation of data; in the writing of the manuscript, or in the decision to publish the results.

\section{References}

1. Bondineau, H.; Sollier, T. Tube support plate clogging up of French PWR steam generators. In Proceedings of the Eurosafe Forum, Paris, France, 3-4 November 2008.

2. Staehle, R.W.; Gorman, J.A. Quantitative assessment of submodes of stress corrosion cracking on the secondary side of steam generator tubing in pressurized water reactors: Part 2. Corrosion 2004, 60, 5-63. [CrossRef] 
3. Schneidmiller, D.; Stiteler, D. Steam Generator Chemical Cleaning Process Development; EPRI NP-3009; Electric Power Research Institute: Palo Alto, CA, USA, 1983.

4. Jeon, S.-H.; Song, G.D.; Hur, D.H. Electrodeposition of magnetite on carbon steel in Fe(III)-triethanolamine solution and its corrosion behavior. Mater. Trans. 2015, 56, 1107-1111. [CrossRef]

5. Song, G.D.; Jeon, S.-H.; Kim, J.G.; Hur, D.H. Effect of polyacrylic acid on the corrosion behavior of carbon steel and magnetite in alkaline aqueous solutions. Corrosion 2016, 72, 1010-2010. [CrossRef]

6. Song, G.D.; Jeon, S.-H.; Son, Y.H.; Kim, J.G.; Hur, D.H. Galvanic effect of magnetite on the corrosion behavior of carbon steel in deaerated alkaline solutions under flowing conditions. Corros. Sci. 2018, 131, 71-80. [CrossRef]

7. Jeon, S.-H.; Song, G.D.; Hur, D.H. Corrosion behavior of alloy 600 coupled with electrodeposited magnetite in simulated secondary water of PWRs. Mater. Trans. 2015, 56, 2078-2083. [CrossRef]

8. Jeon, S.-H.; Song, G.D.; Hur, D.H. Galvanic corrosion between alloy 690 and magnetite in alkaline aqueous solutions. Metals 2015, 5, 2372-2382. [CrossRef]

9. Song, G.D.; Jeon, S.-H.; Kim, J.G.; Hur, D.H. Synergistic effect of chloride ions and magnetite on the corrosion of Alloy 690 in alkaline solutions. Corrosion 2017, 73, 216-220. [CrossRef]

10. Varrin, R., Jr. Characterization of PWR Steam Generator Deposits; EPRI TR-106048; Electric Power Research Institute: Palo Alto, CA, USA, 1996.

11. Tapping, R.L.; Turner, C.W.; Thompson, R.H. Steam generator deposits-A detailed analysis and some inferences. Corrosion 1991, 47, 489-495. [CrossRef]

12. Tsuda, N.; Nasu, K.; Fujimori, A.; Siratori, K. Electrical Conduction in Oxides; Springer: New York, NY, USA, 2000.

13. Forch, H.; Oliver, T.; Hertle, W. Chemical cleaning of PWR steam generators with a low temperature process. Nucl. Eng. Des. 1993, 147, 115-118. [CrossRef]

14. Puzzuoli, F.V.; Leinonen, P.J.; Lowe, G.A.; Murchie, B. Steam generator cleaning campaigns at bruce A: 1993-1996. In Proceedings of the Fourth International Conference CANDU Maintenance, Toronto, ON, Canada, 16-18 November 1997.

15. Itai, R.; Shibuya, M.; Matsumura, T.; Ishi, G. Electrical resistivity of magnetite anodes. J. Electrochem. Soc. 1971, 118, 1709-1711. [CrossRef]

16. Allen, P.D.; Hampson, N.A.; Tyson, J.F. The differential capacitance of magnetite. Surf. Technol. 1979, 9, 395-400. [CrossRef]

17. Zebardast, H.R.; Rogak, S.; Asselin, E. Use of EIS to measure the rate of $\mathrm{H}_{2} \mathrm{O}_{2}$ decomposition on a bulk magnetite electrode in alkaline solution. J. Electrochem. Soc. 2012, 159, B831-B838. [CrossRef]

18. Jung, K.S.; Pierrefeu, L. Electrochemical characterization of sintered magnetite electrode in LiOH solution. Corros. Sci. 2010, 52, 817-825. [CrossRef]

19. Stenberg, T.; Vuoristo, P.; Keranen, J.; Mantyla, T.; Buchler, M.; Virtanen, S.; Schmuki, P.; Bohni, H. Characterization of r.f.-sputtered iron oxide films for modeling passive films. Thin Solid Films 1998, 312, 46-60. [CrossRef]

20. Jeon, S.-H.; Song, G.D.; Hur, D.H. Effects of deposition potentials on the morphology and structure of iron-based films on carbon steel substrate in an alkaline solution. Adv. Mater. Sci. Eng. 2016, 2016, 9038478. [CrossRef]

21. Jeon, S.-H.; Choi, W.I.; Song, G.D.; Son, Y.H.; Hur, D.H. Influence of surface roughness and agitation on the morphology of magnetite films electrodeposited on carbon steel substrates. Coatings 2016, 6, 62. [CrossRef]

22. Kothari, H.M.; Kulp, E.A.; Limmer, S.J.; Poizot, P.; Bohannan, E.W.; Switzer, J.A. Electrochemical deposition and characterization of $\mathrm{Fe}_{3} \mathrm{O}_{4}$ films produced by the reduction of $\mathrm{Fe}(\mathrm{III})$-triethanolamine. J. Mater. Res. 2006, 21, 293-301. [CrossRef]

23. Goujon, C.; Pauporte, T.; Mansour, C.; Delaunary, S.; Bretelle, J.-L. Electrochemical deposition of thick iron oxide films on nickel based superalloy substrates. Electrochim. Acta 2015, 176, 230-239. [CrossRef]

24. Al-Mayouf, A.M. Dissolution of magnetite coupled galvanically with iron in environmentally friendly chelant solutions. Corros. Sci. 2006, 48, 898-912. [CrossRef]

25. Hur, D.H.; Choi, M.S.; Kim, U.C.; Han, J.H. Magnetite dissolution and corrosion behavior in high temperature EDTA solvents. Nucl. Eng. Des. 2003, 220,11-16. [CrossRef]

26. Motekaitis, R.J.; Cox, X.B.; Taylor, P.; Martell, A.E.; Miles, B.; Tvedt, T.J. Thermal degradation of EDTA chelates in aqueous solution. Can. J. Chem. 1982, 60, 1207-1213. [CrossRef] 
27. Motekaitis, R.J.; Hayes, D.; Martell, A.E.; Frenier, W.W. Hydrolysis and ammonolysis of EDTA in aqueous solution. Can. J. Chem. 1979, 57, 1018-1024. [CrossRef]

28. Martell, A.E.; Motekaitis, R.J.; Fried, A.R.; Wilson, J.S.; Macmillan, D.T. Thermal decomposition of EDTA, NTA, and nitrilotrimethylenephosphonic acid in aqueous solution. Can. J. Chem. 1975, 53, 3471-3476. [CrossRef] 